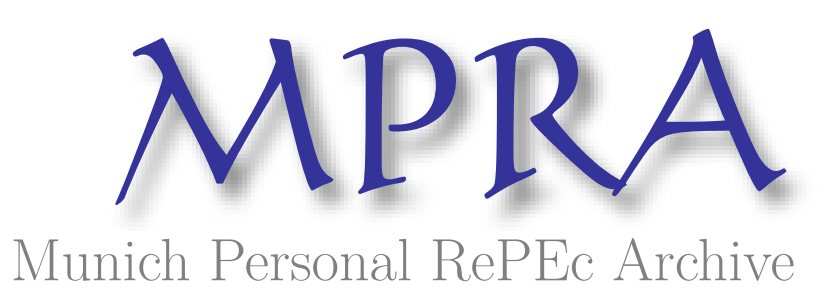

\title{
Central bank digital currency research around the World: a review of literature
}

Ozili, Peterson K

January 2022

Online at https://mpra.ub.uni-muenchen.de/111389/

MPRA Paper No. 111389, posted 06 Jan 2022 06:23 UTC 


\title{
Central bank digital currency research around the World: a review of literature
}

\author{
Peterson K. Ozili
}

\begin{abstract}
This paper reviews the recent advances in central bank digital currency research in a way that would help researchers, policy makers and practitioners to take a closer look at central bank digital currency (CBDC). The review shows a general consensus that a central bank digital currency is a liability of the issuing central bank and it has cash-like attributes. The review also presents the motivation and benefits of issuing a central bank digital currency such as the need to improve the conduct of monetary policy, the need to enhance the efficiency of digital payments and the need to increase financial inclusion. The review also shows that many central banks are researching the potential to issue CBDCs due to its many benefits. However, a number of studies have called for caution against over-optimism about the potential benefits of CBDC due to the limiting nature of CBDC design and its inability to meet multiple competing goals. Suggested areas for future research are identified such as the need to find the optimal CBDC design that meets all competing objectives, the need for empirical evidence on the effect of CBDC on the cost of credit and financial stability, the need to undertake country-specific and regional case studies of CBDC design, and the need to find a balance between limiting the CBDC holdings of users and allowing users to hold as much CBDC as they want. The implication of the findings of this review is that central bankers need to pay more attention to the design features of CBDC. Central bankers need to first identify the goals they want to achieve with CBDC, and design the CBDC to have those features. Where possible, there should be opportunities to re-design and re-invent the CBDC to meet changing central bank objectives.
\end{abstract}

JEL code: E42, E44, E52, E58.

Keywords: Digital currency, Money, Central bank digital currency, CBDC, Digital finance, Cryptocurrency, Financial inclusion, CBDC design, Blockchain, Distributed ledger technology.

This version: January 2022

Published in: Journal of Money Laundering Control 


\section{Introduction}

This paper provides a thematic review of central bank digital currency (CBDC) research. It is important to understand the events that led to the rise of CBDCs. It is also important to take stock of research knowledge about CBDC and provide an understanding of its potential implications for the economy and society.

The rapid shift in focus from 'Fintech' which emerged in the last decade and then to 'cryptocurrency' and then to 'CBDC' which is a more recent innovation shows that the digital finance landscape is changing very rapidly. The cryptocurrency boom between 2017 to 2021 witnessed an influx of private cryptocurrencies especially between 2019 to 2021 such as bitcoins, dogecoin, ethereum, litecoin, etc. Although limited in supply, people held cryptocurrency either as a medium of exchange or as an investment asset class. The limited supply of cryptocurrency and the high demand for cryptocurrency led to a significant increase in the price of cryptocurrencies and crypto-backed assets (Katsiampa et al, 2019). This made cryptocurrency become a profitable asset. Also, the high volatility of cryptocurrency made it become unreliable for use as a medium of exchange. Despite the high volatility of cryptocurrency, an increasing number of people in many countries began trading in cryptocurrency while bearing huge risk of losses on themselves. Some central banks responded to this by placing an outright ban on cryptocurrency such as China, Bolivia, Indonesia, Turkey and Egypt. Other central banks issued statements warning citizens that they use cryptocurrency at their own risk such as Singapore, Ireland, Kenya, Nigeria and the United Kingdom. Soon, some central banks formally announced that they plan to issue a CBDC as an alternative form of money, while for some central banks, the unofficial reason for issuing a CBDC is for CBDC to become the government's counter-reaction to private digital currencies which are managed by unknown entities.

The volume of CBDC research on central bank digital currency has grown over the last five years. The increase in the volume of CBDC research is due to digital payments innovations and a number of other factors, including innovations in digital finance, the rise in blockchain-enabled distributed ledger technologies, the dominance of cryptocurrency in the digital currency space, and the need to curb illicit cryptocurrency-induced criminal activities. There are two particular reasons for this review. First, this review seeks to identify the major research themes in the emerging CBDC 
literature in an effort to help researchers, policymakers and practitioners to take a closer look at CBDC. Second, this review seeks to highlight the areas of the CBDC debate that are receiving increasing attention from commentators, academics, policy makers and critics in recent times. Although CBDC has its critics who claim that CBDC will not be as successful as it is being promoted (Terracciano and Somoza, 2020), proponents of CBDC claim that CBDC has positive benefits for the economy and society. The importance of this review paper is further underpinned by the fact that review papers on CBDC is scarce in the literature. This paper builds on the review of Carapella and Flemming (2020) and Kiff et al (2020), and seeks to delineate the key themes in CBDC research which were not highlighted by Carapella and Flemming (2020) and Kiff et al (2020).

The rest of the paper is structured as follows. Section 2 presents the conceptual framework for CBDC. Section 3 presents the major themes in CBDC research. Section 4 present a review of CBDC research around the world. Section 5 suggests some areas for future CBDC research. Section 6 concludes.

\section{Conceptual framework}

This section presents a discussion of the definitions of CBDC, CBDC in the finance and economics disciplines, the motivation and benefits of issuing a CBDC as well as the difference between tokenbased CBDC and account-based CBDC.

\subsection{CBDC definitions}

In simple terms, a CBDC is a currency in digital form that is issued by a central bank and is a liability of the issuing central bank. A lay person could see a CBDC as the digital equivalent of central bank-issued paper currencies. There are more sophisticated definitions of CBDC in the literature. For example, Ward and Rochemont (2019) define a CBDC as a digital form of central bank money that is different from the balances in traditional reserve or settlement accounts. Bitter (2020) defines a CBDC as a potentially interest bearing, centrally issued, account based, digital type of central bank liability that is accessible to the general public. Kumhof and Noone (2018) define a CBDC as electronic central bank money that (i) can be accessed more broadly than 
reserves, (ii) has much greater functionality for retail transactions than cash, (iii) has a separate operational structure compared to other forms of central bank money, allowing it to potentially serve a different core purpose (p.4). Kiff et al (2020) define CBDC as a digital representation of a sovereign currency issued by, and is a liability of, a jurisdiction's central bank or other monetary authority. Bordo and Levin (2017) and Engert and Fung (2017) define a central bank digital currency as a monetary value stored electronically that represents a liability of the central bank and can be used to make payments. Ozili (2021b) defines digital currency as fiat digital money issued by a central bank. These definitions collectively show that a CBDC is a liability of the issuing central bank and is different from cash in its physical attributes even though a CBDC has the same function as cash such as to make payments.

\subsection{Contextualizing CBDC in the digital finance and economics disciplines}

A question that often arises about CBDC is which discipline does CBDC belong to. I show that CBDC belongs to the finance and economics disciplines. In the finance discipline, CBDC can be classified under digital finance. Digital finance is the branch of finance that explore the innovations that enable the delivery of financial products and services through digital devices over the internet (Ozili, 2018). Therefore, CBDC can be regarded as one of the many advancements in 'digital finance' which is a sub-field of the finance discipline. In the economics discipline, CBDC can be classified under monetary economics. Monetary economics is the branch of economics that analyzes money, its features, its functions and the acceptance of money in the economic system (Lewis and Mizen, 2000). Therefore, CBDC can be regarded as a new type of money in the field of monetary economics which is a sub-field of the economics discipline. Figure 1 below helps to understand the positioning of CBDC in the economics and finance disciplines. 
Figure 1: Positioning CBDC in the economics and finance disciplines

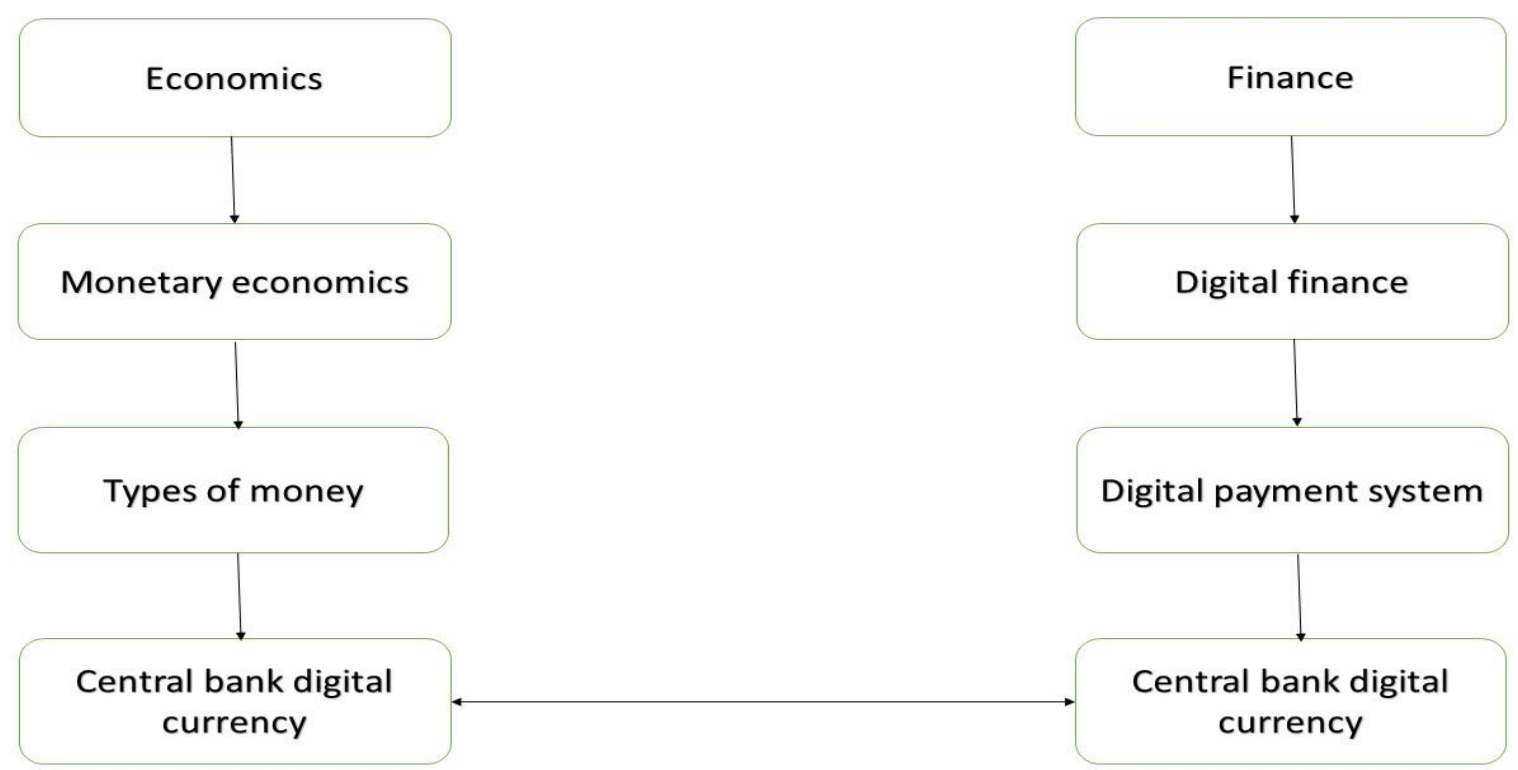

\subsection{Motivation and benefits of issuing CBDC}

There are several motivations for issuing a CBDC in the literature. They include the need to support unconventional monetary policy (Bordo and Levin, 2017), the need to preserve financial stability (Engert and Fung, 2017), the need to increase the level of financial inclusion (Ozili, 2021a), the need to increase the contestability of retail payments (Engert and Fung, 2017), the need to inhibit criminal activity (Engert and Fung, 2017), and the need to issue CBDC as a counterreaction to private cryptocurrency such as bitcoins (Ozili, 2021b). There are several benefits of issuing a CBDC. The literature document that CBDC can be used as an efficient medium of exchange, a secure store of value, an alternative unit of account, it can lead to a decrease in the demand for paper currency, CBDC can enhance monetary policy, CBDC has cash-like attributes, $\mathrm{CBDC}$ can compete with paper money and reduce the cost of producing and managing cash in the economy (see, for example, Bordo and Levin, 2017; Ozili, 2022; Agur et al, 2021). 


\subsection{Account-based CBDC versus token based CBDC}

An account-based CBDC ties a CBDC to an identity system where a sender first verifies whether the receiver has an account and then verifies the identity of the receiver before making a payment or transfer. Basically, with an account-based CBDC, the person sending a CBDC amount verifies the identity of the receiver and whether the receiver holds an account (Terracciano and Somoza, 2020). A token-based CBDC is not tied to an identity system. Rather, a token-based CBDC ties a CBDC to an access technology based on digital tokens (Auer and Böhme, 2020). With a tokenbased CBDC, a person verifies the authenticity of the token for every payment transaction (Terracciano and Somoza, 2020). A CBDC token is a digital object that has a given value expressed in the national unit of account and is a claim on the central bank (Armelius et al, 2021). Most times, the CBDC token is stored remotely not on local devices. Another difference is that tokenbased CBDCs can be traded offline while account-based CBDC transactions cannot be executed without the system remotely validating the identity of the account holder and the balance on the account (Terracciano and Somoza, 2020).

\section{Major research themes in the CBDC literature}

This section explores the dominant research themes in the CBDC literature. The themes include the literature on CBDC adoption and development, $\mathrm{CBDC}$ and financial inclusion, $\mathrm{CBDC}$ and the functions and objectives of a central bank, the design of CBDC, the welfare effects of CBDC, the role of CBDC for macroeconomic and financial stability, and lastly, CBDC and bank competition.

\subsection{CBDC adoption and development}

Boar and Wehrli (2021) undertook a survey of CBDC adoption, and found that the vast majority of central banks, about $86 \%$ of central banks, were actively researching the potential to issue a CBDC, $60 \%$ of central banks were experimenting with the technology and $14 \%$ of central banks were in the development and pilot stages of CBDC. Náñez Alonso et al (2021) analyse CBDC status in countries like the Bahamas, China and Uruguay. They found that these countries are at different stages of CBDC development. Ozili (2021c), in a survey of CBDC adoption by African countries, found that only 7 African countries have officially declared interest in central bank 
digital currency. Only 4 African countries had reached the pilot test stage of central bank digital currency adoption. Only 3 African countries have a very robust payment system infrastructure that can support central bank digital currency while Nigeria is the only African country that has adopted a central bank digital currency as of 2021. Interestingly, 78 per cent of African countries have not shown interest in central bank digital currency while the West African region had the highest number of countries that have not shown any interest in CBDCs as of 2021.

\subsection{CBDC and financial inclusion}

Several studies in the central bank digital currency literature have predicted a relationship between central bank digital currency and financial inclusion. Ozili (2021a) show that CBDC can promote financial inclusion by digitizing the value chains in the economy, improving access to digital financial services, enlarging the digital economy, enhancing the efficiency of digital payments and reducing transaction cost. Foster et al (2021) argue that a central bank digital currency can accelerate financial inclusion in excluded populations by giving people access to central bank currency in a wallet issued by Fintech agents so that the very poorest are able to avoid the high costs charged by banks and mobile money providers. Andolfatto (2021) argues that an interestbearing central bank digital currency may reduce the demand for cash and increase financial inclusion while Ozili (2021b) show that central bank digital currency can promote financial inclusion when a central bank digital currency is designed to make people hold amounts of central bank digital currency without needing a bank account. Engert and Fung (2017) point out that financial inclusion is an important reason for adopting a central bank digital currency in emerging countries. Mancini-Griffoli et al (2018) argue that a central bank digital currency can encourage financial inclusion only if it is attractive as an alternative form of money. They further argue that the demand for CBDC will not be very high when there is low aversion to use formal finance especially in countries that have a large informal sector. Barontini and Holden (2019), in their analysis of a CBDC survey, show that one of the reasons why central banks are issuing a central bank digital currency is to broaden financial inclusion goals. They argue that even though many central banks are not yet convinced that the benefits of a central bank digital currency will outweigh the costs, emerging countries appear to be interested in the financial inclusion benefits of a retail central bank digital currency than developed countries. Maniff (2020) argues that a central bank digital currency created for financial inclusion purposes should complement cash and 
not replace cash. Maniff (2020) also points out that a central bank digital currency designed to maximize financial inclusion may be less effective in achieving other goals. Didenko and Buckley (2021) argued that a well-designed central bank digital currencies can offer a viable solution to the financial inclusion problems in the Pacific region. However, they urge regulators in the Pacific region to spend more time in studying $\mathrm{CBDC}$ to build specific knowledge and expertise to issue a well-designed central bank digital currency.

\subsection{CBDC and the functions and objectives of central banks}

Regarding enhancing central bank objectives and functions, Cukierman (2019) argue that, for central banks to preserve the effectiveness of monetary policy in a world that is increasingly flooded by private digital currencies, central banks will have to issue their own digital currencies. Bordo and Levin (2017) investigate how a central bank digital currency could facilitate the transparent conduct of monetary policy. They show that central bank digital currency can become a costless medium of exchange, a secure store of value and a stable unit of account only if central bank digital currencies are account-based and interest-bearing. Boar et al (2020) show that even though central banks plan to issue a central bank digital currency, they will need to collaborate with other central banks to better understand the impact of private digital tokens for central bank digital currency payments. Fernández-Villaverde et al (2020) show that the introduction of central bank digital currency presents an impossible central bank digital currency trilemma for central banks which are the goals of efficiency, financial stability and price stability. They argue that CBDC enables the attainment of only two central bank goals at the same time. Also, Bjerg (2017) argues that a monetary system that has two competing money creators - the central bank and the commercial banking sector - can simultaneously only pursue two out of the following three policy objectives: (i) free convertibility between CBDC and bank money, (ii) parity between CBDC and bank money, and (iii) central bank monetary sovereignty. Barontini and Holden (2019) show that, while most central banks are conducting research into central bank digital currency, only a limited number of central banks are at the pilot stage with central bank digital currencies, and even fewer central banks see the issuance of a central bank digital currency as a short or medium term goal. 


\subsection{The design of CBDC}

Regarding the design of central bank digital currency, Lee et al (2021) argue that central banks that are adopting central bank digital currencies will have to choose the choice of ledger. They will determine whether the central bank digital currency should be based on distributed ledger technology or the traditional central bank infrastructure. Lee et al (2021) also show that countries that are conversant with the distributed ledger technology will have a competitive advantage in developing a central bank digital currency. They show that, after implementing the central bank digital currency, there will be a need to continuously review existing regulations to support central bank digital currency, and there may be a need to modify central bank digital currency whenever international dynamics change the central bank digital currency landscape. Bossu et al (2020) investigate the capability of a central bank digital currency to acquire the status of official means of payment. They state that token-based central bank digital currency and account-based central bank digital currency are two different forms of money, and the legal treatment of the two types of central bank digital currency will depend on the design features of a central bank digital currency. They show that central bank digital currency is a central bank liability incorporated in a digital token and transferred to users. Auer et al (2020) show that more central banks are issuing retail central bank digital currency architectures in which the central bank digital currency is a direct cash-like claim on the central bank. Engert and Fung (2017) argue that issuing central bank digital currencies in order to increase the contestability in retail payments may not be a very valid reason to issue central bank digital currency because such impact depends on the specific attributes of the central bank digital currency.

\subsection{Welfare effects of CBDC}

Regarding the welfare effects of a central bank digital currency, Auer and Böhme (2020) show that central bank digital currencies can offer cash-like safety and convenience for peer-to-peer payments. Davoodalhosseini (2021), in a Canadian case study, examine a monetary policy design where only cash, only central bank digital currency, or both cash and central bank digital currency are available to economic agents. They show that if the cost of using central bank digital currency is not too high, economic agents will prefer to use central bank digital currencies than cash. Also, having both cash and central bank digital currency available could lead to lower welfare than when only cash or only central bank digital currency is available. Söilen and Benhayoun (2021) use a 
survey questionnaire to assess the acceptance of central bank digital currencies by households. They show that the adoption of central bank digital currencies by households was partly due to social recommendations. Ward and Rochemont (2019) show that many central banks promote CBDC even though the international community has divided opinions on the potential benefits of CBDC itself.

\subsection{CBDC and macroeconomic and financial stability}

Regarding the macroeconomic and financial stability benefits of a central bank digital currency, Yao (2018) argues that the development of central bank digital currency in China could make money become a more stable value, and could offer effective tools for macroeconomic control. Williamson (2019) constructs a model of multiple means of payment to analyze the effect of the central bank digital currency on payments. Williamson (2019) shows that central bank digital currency mitigates crime associated with physical currency, and it permits the payment of interest on a key central bank liability. Kim and Kwon (2019) examine the implications of central bank digital currency for financial stability using a monetary general equilibrium model. They show that the introduction of deposits in central bank digital currency account will decrease the supply of private credit by commercial banks, which will raise the nominal interest rate and lower the reserve-to-deposit ratio of commercial banks. This can have a negative effect for financial stability by increasing the likelihood of bank panic in which commercial banks are short of cash reserves to pay out to depositors. Regarding the risks and spillovers of central bank digital currency, Ferrari et al (2020) examine central bank digital currency in an open-economy. They show that the presence of a central bank digital currency can significantly amplify global spillovers of shocks. But the magnitude of these effects will depend on the specific design of central bank digital currency, and the effects can be significantly dampened if the central bank digital currency possesses risk-mitigation features. 


\subsection{CBDC and bank competition}

Regarding competition with banks, Chiu et al (2019) point out that if banks have market power in the deposit market, an interest-bearing central bank digital currency can enhance competition, raise the deposit rate, expand intermediation and increase output. Andolfatto (2021) shows that introducing interest-bearing central bank digital currency can diminish the demand for cash. Also, the introduction of interest-bearing central bank digital currency may not disintermediate banks rather it can expand their depositor base if the added competition compels banks to raise interest on customer deposits. Agur et al (2021) examine central bank digital currency in an environment where users are allowed to freely choose between using cash, central bank digital currency, and bank deposits according to their preferences for anonymity and security. They show that a central bank digital currency that competes with deposits could depress bank credit and output. In contrast, a cash-like central bank digital currency may lead to the disappearance of cash over time. Grym et al (2017) argue that central bank digital currencies can make banknotes become a technically outdated payment instrument.

\subsection{On the security risk and privacy challenges of CBDC}

Rennie and Steele (2021) outline the policy choices involved in designing a CBDC and the consequences of these choices for privacy. They argue that central banks have a number of priorities which could eventually undermine privacy such as preventing the criminal abuse of the financial system, geopolitical concerns and private sector innovation. They further argue that the current CBDC models possess privacy risk which could materialize into losses such as the loss of anonymity, loss of liberty, loss of individual control and loss of regulatory control. Grothoff and Moser (2021) argue that a privacy-preserving CBDC must ensure legal compliance and compliance with anti-money laundering (AML) and combating the financing of terrorism (CFT) laws. They further argue that a CBDC can attain the transaction privacy property of cash only when CBDC is deployed on token-based systems. Darbha and Arora (2020) outline what is technologically feasible for privacy in a central bank digital currency (CBDC) system. They point out that the main issue is about what type of information to keep private and who to keep it private from. But many people see privacy differently. Nonetheless, they show that what is technologically feasible for central banks to do is to (i) choose cryptographic techniques and operational arrangements that have an in-built privacy design; (ii) engineer a CBDC system with higher levels 
of privacy but this comes with trade-offs since requesting for more information from users may lead to excessive complexity and risk; and (iii) the user's overall privacy will depend on factors such as user behaviour and the privacy policies of other entities in the CBDC ecosystem. Regarding CBDC security, Minwalla (2020) explores the security aspects involved in constructing and deploying a central bank digital currency. The author show that (i) security must permeate the design of a CBDC from inception for all use-cases of a CBDC and there is need for operational security through continuous testing, authentication safeguards, adherence to best practices and periodic external audits of key system components; (ii) central banks must ensure that the permissioned distributed ledger technology (DLT) systems which central banks use to deploy a CBDC have additional security safeguards; (iii) there is need to provide dedicated single-purpose devices that store value locally as they are robust against network-level attacks or natural disruption; this will ensure that the stored value offer extreme resilience, and (iv) the central bank should put in place suitable controls and processes to mitigate the risk of large-scale attacks from foreign attackers.

\section{CBDC research around the world}

This section reviews some regional or country-specific studies on CBDC in the literature. The studies in table 1 shows that most of the CBDC studies are explorative studies and there are no empirical studies on CBDC. The lack of empirical studies is due to the fact that CBDCs are still a relatively new concept. Also, table 1 shows that there are very few country-specific studies on CBDC possibly because CBDCs have not been adopted in many countries. 
Table 1: Some CBDC research around the world

\begin{tabular}{|c|c|c|c|c|}
\hline \multicolumn{5}{|c|}{ Table 1: Some CBDC research around the world } \\
\hline Region & Studies & Purpose & Method & Findings \\
\hline \multirow[t]{2}{*}{ Africa } & Ozili (2021b) & $\begin{array}{l}\text { To discuss the } \\
\text { features, } \\
\text { opportunities and } \\
\text { risks of CBDC in } \\
\text { Nigeria }\end{array}$ & $\begin{array}{l}\text { Explorative } \\
\text { study }\end{array}$ & $\begin{array}{l}\text { The author show that the eNaira can improve monetary policy } \\
\text { transmission, offer efficient payments and increase financial } \\
\text { inclusion. Some of the identified risks include rising digital } \\
\text { illiteracy, increased propensity for cyber-attacks, data theft, and } \\
\text { the uncertain role of banks in a full-fledged CBDC economy. }\end{array}$ \\
\hline & Ozili (2021c) & $\begin{array}{l}\text { A survey of } \\
\text { CBDC adoption } \\
\text { in African } \\
\text { countries }\end{array}$ & $\begin{array}{l}\text { Survey } \\
\text { using } \\
\text { secondary } \\
\text { data }\end{array}$ & $\begin{array}{l}\text { The author finds that } 78 \text { per cent of African countries have not } \\
\text { shown interest in CBDC. Only } 3 \text { African countries have a very } \\
\text { robust payment system infrastructure that can support CBDC. } \\
\text { Only } 8 \text { African countries have announced that they are studying } \\
\text { CBDC. Only one African country has adopted CBDC. }\end{array}$ \\
\hline \multirow[t]{3}{*}{ Asia } & Yao (2018) & $\begin{array}{l}\text { To analyze the } \\
\text { essence and } \\
\text { connotation of } \\
\text { China's digital } \\
\text { fiat currency }\end{array}$ & $\begin{array}{l}\text { Explorative } \\
\text { study }\end{array}$ & $\begin{array}{l}\text { The author concludes that China's digital fiat currency is a } \\
\text { credit-based currency in terms of value, a crypto-currency from a } \\
\text { technical perspective, an algorithm-based currency in terms of } \\
\text { implementation and a smart currency } \\
\text { in application scenarios. }\end{array}$ \\
\hline & $\operatorname{Kim}(2020)$ & $\begin{array}{l}\text { To discuss the } \\
\text { importance of } \\
\text { CBDC and } \\
\text { identify the } \\
\text { characteristics of } \\
\text { China's CBDC }\end{array}$ & $\begin{array}{l}\text { Discourse } \\
\text { analysis }\end{array}$ & $\begin{array}{l}\text { The motivation to issue CBDC in China resulted from (i) the rise } \\
\text { of Bitcoin and various cryptocurrencies, (ii) the entry of big tech } \\
\text { firms into financial services, and (iii) the unexpected intense } \\
\text { debate concerning Libra and other stable coins. The main } \\
\text { characteristics of China's CBDC are (i) a two-tier CBDC } \\
\text { system, and (ii) the distributed ledger technology }\end{array}$ \\
\hline & $\begin{array}{l}\text { Priyadarshini } \\
\text { and Kar } \\
(2021)\end{array}$ & $\begin{array}{l}\text { To discuss } \\
\text { conceptual issues } \\
\text { to consider when } \\
\text { issuing CBDC in } \\
\text { India }\end{array}$ & $\begin{array}{l}\text { Discourse } \\
\text { analysis }\end{array}$ & $\begin{array}{l}\text { Author concludes that the Indian authorities should take into } \\
\text { account monetary sovereignty issues, national sovereignty } \\
\text { issues, and developmental issues when planning to issue a } \\
\text { CBDC for India. }\end{array}$ \\
\hline \multirow[t]{2}{*}{ Oceania } & $\begin{array}{l}\text { Wadsworth } \\
\text { (2018) }\end{array}$ & $\begin{array}{l}\text { To discuss the } \\
\text { cost and benefits } \\
\text { of issuing CBDC } \\
\text { for public use in } \\
\text { New Zealand. }\end{array}$ & $\begin{array}{l}\text { Discourse } \\
\text { analysis }\end{array}$ & $\begin{array}{l}\text { Author concludes that issuing a CBDC in New Zealand will } \\
\text { present a mix of pros and cons for payments efficiency and } \\
\text { resiliency. Changes in CBDC design can mitigate some of the } \\
\text { cons. The CBDC can lead to cost savings for currency } \\
\text { distribution, and could also create new costs. }\end{array}$ \\
\hline & Emery (2019) & $\begin{array}{l}\text { To explore } \\
\text { Australia's New } \\
\text { Payments } \\
\text { Platform (NPP) } \\
\text { and its ability to } \\
\text { deliver world- } \\
\text { class retail } \\
\text { payments } \\
\text { solution }\end{array}$ & $\begin{array}{l}\text { Discourse } \\
\text { analysis }\end{array}$ & $\begin{array}{l}\text { The author concludes that there is no strong reason for the } \\
\text { Reserve Bank of Australia to issue a retail CBDC given that } \\
\text { Australia's New Payments Platform (NPP) already provides a } \\
\text { very fast real-time retail payments system. }\end{array}$ \\
\hline
\end{tabular}




\section{Areas for future research}

In this section, I suggest some avenues for future research on central bank digital currency.

\subsection{Finding the optimal CBDC design that meets multiple competing objectives}

Currently, it is difficult for CBDC to meet multiple competing goals. Designing a CBDC to meet one objective often prevent the CBDC from meeting other important objectives. For example, designing a CBDC to increase financial inclusion can make it difficult to curb digital money fraud because high know-your-customer (KYC) standards need to be lowered to promote financial inclusion for unbanked adults who cannot meet most of the documentation requirements. Also, designing a CBDC to achieve price stability and financial stability can make it difficult, or almost impossible, to achieve the goal of CBDC efficiency. There is a need to find the optimal CBDC design that meets multiple competing objectives of a CBDC. Future studies should explore the optimal design of a CBDC that meets multiple objectives for financial system and macroeconomic stability.

\subsection{Empirical evidence on the effect of CBDC on the cost of credit and financial stability}

There is no empirical evidence for the effect of CBDC on the cost of credit and financial stability in the CBDC literature. There is a need to explore the effect of CBDC on the cost of credit and financial stability. The expectation is that when CBDCs are introduced as substitutes to cash, the widespread adoption of CBDC may lead to a fall in the volume of deposits held by banks. The fall in the volume of bank deposits can increase the cost of credit as banks will have little deposits to lend from. The resulting high cost of credit can trigger financial instability. This expectation, however, needs to be supported or refuted using available CBDC data. Future studies should investigate the likely impact of CBDC adoption on the cost of credit and financial stability.

\subsection{Finding a balance between limiting CBDC holdings and preserving user choice and preference}

Placing a limit on CBDC deposits makes it less attractive compared to cash. In the end, it can lead to more preference for cash as there is no limit to the amount of cash a person can hold and there is no limit on the volume of bank deposits in a depositor's bank account. Although placing a limit 
on CBDC holdings is done for regulatory reasons, it denies the user the choice to hold as many units of CBDC as possible. This can make more people prefer cash payments and abandon CBDC. So, there is a need to find a balance between limiting CBDC holdings and user's preference. Future studies should find a balance between limiting the CBDC holdings of users and allowing users to hold as much CBDC as they want - so as not to discourage users from using CBDC to the fullest.

\subsection{Explore country-specific and regional case studies of CBDC design}

A comparative analysis of CBDC design in individual countries and regions have not been explored in the literature. There are opportunities for future research in this area. From a regional case study, we can gain insight about collective design features of CBDC while the individual country-cases can reveal the modifications made to the local CBDC to meet the needs of the local economy. It would be interesting to identify the attributes of a regional CBDC and the attributes of country-specific CBDC. Future studies can also compare the CBDC attributes of one region with that of another region, and also make a comparison of CBDC attributes across countries.

\section{Conclusion}

This paper reviewed the definitions of CBDC in the literature. The literature showed a general consensus that a CBDC is a liability of the central bank and has cash-like attributes. The review also presented the motivations and benefits of issuing a CBDC such as the need to increase financial inclusion, the need to improve the conduct of monetary policy and to enhance digital payments efficiency, etc. The review also showed that a majority of central banks are researching the potential to issue a CBDC due to its many benefits. However, a number of studies have called for caution against over-optimism about the potential benefits of CBDC due to the limiting nature of CBDC designs and its inability to meet multiple competing goals. The paper suggested some areas for future research such as the need to find the optimal CBDC design that meets all competing objectives, the need for empirical evidence on the effect of CBDC on cost of credit and financial stability, the need to explore country-specific and regional case studies of CBDC design, and the need to find a balance between limiting the CBDC holdings of users and allowing users to hold as much CBDC as they want - so as not to discourage users from using CBDC to the fullest. 
The implication of the findings of this review is that central bankers need to pay more attention to the design features of CBDC. Central bankers need to first identify the goals they want to achieve with CBDC, and design the CBDC to have those features. Where possible, there should be opportunities to re-design and re-invent the CBDC to meet changing central bank objectives. More importantly, central banks must place a high premium on CBDC security and privacy at all times. Although this will come at a high cost, central banks believe that no cost is too high to bear to issue a national central bank digital currency. Finally, it is too early to know what the actual benefits and consequences of CBDCs will be, whether it will yield the expected outcomes, and whether CBDCs can live up to its promise. Only the future will tell.

\section{Reference}

Agur, I., Ari, A., \& Dell'Ariccia, G. (2021). Designing central bank digital currencies. Journal of Monetary Economics. Forthcoming

Andolfatto, D. (2021). Assessing the impact of central bank digital currency on private banks. The Economic Journal, 131(634), 525-540.

Armelius, H., Claussen, C. A., \& Hull, I. (2021). On the possibility of a cash-like CBDC. Sveriges Riksbank Staff memo.

Auer, R., \& Böhme, R. (2020). The technology of retail central bank digital currency. BIS Quarterly Review, March.

Auer, R. A., Cornelli, G., \& Frost, J. (2020). Rise of the central bank digital currencies: drivers, approaches and technologies (No. 8655). CESifo Working Paper.

Barontini, C., \& Holden, H. (2019). Proceeding with caution-a survey on central bank digital currency. Proceeding with Caution-A Survey on Central Bank Digital Currency (January 8, 2019). BIS Paper, (101). Basel, Switzerland. 
Bitter, L. (2020). Banking Crises under a Central Bank Digital Currency (CBDC). Conference Paper, Beiträge zur Jahrestagung des Vereins für Socialpolitik 2020: Gender Economics, ZBW Leibniz Information Centre for Economics, Kiel, Hamburg

Bjerg, O. (2017). Designing new money-the policy trilemma of central bank digital currency. CBS Working Paper, June.

Boar, C., Holden, H., \& Wadsworth, A. (2020). Impending arrival-a sequel to the survey on central bank digital currency. BIS paper, (107).

Boar, C., \& Wehrli, A. (2021). Ready, steady, go? Results of the third BIS survey on central bank digital currency. BIS Papers, No 114.

Bordo, M. D., \& Levin, A. T. (2017). Central bank digital currency and the future of monetary policy (No. w23711). National Bureau of Economic Research.

Bossu, W., Itatani, M., Margulis, C., Rossi, A. D., Weenink, H., \& Yoshinaga, A. (2020). Legal aspects of central bank digital currency: Central bank and monetary law considerations. IMF Working Paper No. 20/254, Available at SSRN: https://ssrn.com/abstract=3758088

Carapella, F., \& Flemming, J. (2020). Central Bank Digital Currency: A Literature Review. FEDS Notes, (2020-11), 09-1.

Chiu, J., Davoodalhosseini, S. M., Hua Jiang, J., \& Zhu, Y. (2019). Bank market power and central bank digital currency: Theory and quantitative assessment. Available at SSRN 3331135.

Cukierman, A. (2019). Welfare and political economy aspects of a central bank digital currency. Working Paper, Centre for Economic Policy Research (CEPR).

Darbha, S., \& Arora, R. (2020). Privacy in CBDC technology (No. 2020-9). Bank of Canada.

Davoodalhosseini, S. M. (2021). Central bank digital currency and monetary policy. Journal of Economic Dynamics and Control, 104150.

Didenko, A.N. and Buckley, R.P. (2021). Central Bank Digital Currencies: A Potential Response to The Financial Inclusion Challenges of the Pacific Issues in Pacific Development, No.3. Asian Development Bank. Mandaluyong, Philippines. 
Emery, D. (2019). Fintech and central bank digital currency in Australia (No. 1028). ADBI Working Paper Series.

Engert, W., \& Fung, B. S. C. (2017). Central bank digital currency: Motivations and implications. Bank of Canada Staff Discussion Paper, No. 16

Ferrari, M. M., Mehl, A., \& Stracca, L. (2020). Central bank digital currency in an open economy. ECB Working Paper No. 20202488, Available at SSRN: https://ssrn.com/abstract=3733463

Fernández-Villaverde, J., Schilling, L., \& Uhlig, H. (2020). Central bank digital currency: When price and bank stability collide. CEPR Discussion Paper No. DP15555, Available at SSRN: https://ssrn.com/abstract=3753955

Foster, K., Blakstad, S., Gazi, S., and Bos, M. (2021). Digital currencies and CBDC impacts on least developed countries (LDCs). Dialogue on Global Digital Finance Governance. Technical Paper 1.2. United Nations Development Programme. New York. United States.

Grothoff, C., \& Moser, T. (2021). How to issue a privacy-preserving central bank digital currency? SUERF Policy Brief, 2021(114).

Grym, A., Heikkinen, P., Kauko, K., \& Takala, K. (2017). Central bank digital currency. Bank of Finland (BoF) Economics Review Vol 5.

Katsiampa, P., Corbet, S., \& Lucey, B. (2019). High frequency volatility co-movements in cryptocurrency markets. Journal of International Financial Markets, Institutions and Money, 62, 35-52.

Kiff, M.J., Alwazir, J., Davidovic, S., Farias, A., Khan, M.A., Khiaonarong, M.T., Malaika, M., Monroe, M.H.K., Sugimoto, N., Tourpe, H. and Zhou, P., (2020). A survey of research on retail central bank digital currency. International Monetary Fund, Working Paper, Washington.

Kim, Y. S., \& Kwon, O. (2019). Central bank digital currency and financial stability. Bank of Korea WP 2019-6, Available at SSRN: https://ssrn.com/abstract=3330914

Kim, G. (2020). Why is China going to issue CBDC (Central Bank Digital Currency)? The Journal of Internet Electronic Commerce Research, 20(4), 161-177. 
Kumhof, M., \& Noone, C. (2018). Central bank digital currencies-design principles and balance sheet implications. Bank of England Working Paper No. 725

Lee, D. K. C., Yan, L., \& Wang, Y. (2021). A global perspective on central bank digital currency. China Economic Journal, 14(1), 52-66.

Lewis, M. K., \& Mizen, P. D. (2000). Monetary economics. OUP Catalogue.

Mancini-Griffoli, T., Peria, M. S. M., Agur, I., Ari, A., Kiff, J., Popescu, A., \& Rochon, C. (2018). Casting light on central bank digital currency. IMF staff discussion note, 8. Washington DC.

Maniff, J. L. (2020). Motives Matter: Examining Potential Tension in Central Bank Digital Currency Designs. Federal Reserve Bank of Kansas City: Omaha, NE, USA.

Minwalla, C. (2020). Security of a CBDC (No. 2020-11). Bank of Canada.

Náñez Alonso, S. L., Jorge-Vazquez, J., \& Reier Forradellas, R. F. (2021). Central Banks Digital Currency: Detection of Optimal Countries for the Implementation of a CBDC and the Implication for Payment Industry Open Innovation. Journal of Open Innovation: Technology, Market, and Complexity, 7(1), 72 .

Ozili, P.K. (2018). Impact of digital finance on financial inclusion and stability. Borsa Istanbul Review, 18(4), 329-340.

Ozili, P.K. (2021a). Can central bank digital currency increase financial inclusion? Arguments for and against. Forthcoming

Ozili, P.K. (2021b). Central bank digital currency in Nigeria: opportunities and risks. Available at SSRN 3917936

Ozili, P.K (2021c). A Survey of Central Bank Digital Currency Adoption in African countries. Forthcoming.

Ozili, P.K. (2021d). Central bank digital currency can lead to the collapse of cryptocurrency. Available at SSRN 3850826.

Priyadarshini, D., \& Kar, S. (2021). Central Bank Digital Currency (CBDC): Critical Issues and the Indian Perspective. 
Rennie, E., \& Steele, S. (2021). Privacy and Emergency Payments in a Pandemic: How to Think about Privacy and a Central Bank Digital Currency. Law, Technology and Humans, 3(1), 6-17.

Söilen, K. S., \& Benhayoun, L. (2021). Household acceptance of central bank digital currency: the role of institutional trust. International Journal of Bank Marketing. https://doi.org/10.1108/IJBM04-2021-0156

Terracciano, T., \& Somoza, L. (2020). Central bank digital currency: the devil is in the details. LSE Business Review.

Wadsworth, A. (2018). The pros and cons of issuing a central bank digital currency. Reserve Bank of New Zealand Bulletin, Vol 81, No 7, 1-21. Bulletin

Ward, O., \& Rochemont, S. (2019). Understanding Central Bank Digital Currencies (CBDC). Institute and Faculty of Actuaries.

Williamson, S. (2019). Central bank digital currency: Welfare and policy implications. Unpublished, University of Western Ontario, 4.

Yao, Q. (2018). A systematic framework to understand central bank digital currency. Science China Information Sciences, 61(3), 1-8. 